\title{
Investigation on Ergonomics Awareness Among Video Display Unit Users - A Case Study Among Office Workers in UPNM
}

\author{
DARUIS, D.D.I. and Ramli, S. \\ ${ }^{1}$ Dept. of Mechanical Engineering, Faculty of Engineering, Universiti Pertahanan Nasional \\ Malaysia, Kem Sg. Besi, 57000 Kuala Lumpur, MALAYSIA \\ ${ }^{2}$ Dept. of Computer Science, Faculty of Defence Science, Universiti Pertahanan Nasional \\ Malaysia, Kem Sg. Besi, 57000 Kuala Lumpur, MALAYSIA \\ a dian@upnm.edu.my b suzaimah@upnm.edu.my
}

Keywords: ergonomics awareness, computer ergonomics, Musculoskeletal disorders (MSD), visual display terminal (VDT),

\begin{abstract}
Office ergonomics has been emphasized in many industries and organizations. Health problems such as musculoskeletal disorders and repetitive syndrome injuries are commonly reported by office workers worldwide. The aim of this study is to evaluate the level of awareness and understanding of ergonomics among a local institute of higher learning office workers who use computers every day in their work. Secondly is to identify suitable ergonomics intervention programs for the workers. Survey questionnaires were developed as online survey and the link was emailed to all staff. However, questionnaire in hardcopies were also prepared and manually distributed to all the different departments in UPNM such as the Registrar, Bursary, HEPA, Library, Publisher, as well as Centres and Faculties. The number respondents were 50 out of 120 staffs and $62 \%$ of the respondents were female. Questionnaires were divided into sections to get information on the demographic background, to evaluate the level of awareness regarding ergonomics, to determine ergonomics trainings or exposures experienced, to investigate any problems related to health problems or discomfort and workstations as well as physiological and psychological complaints. The hyphothesis that the University's workers have very little knowledge regarding office ergonomics and yet some of them have already experience work-related musculoskeletal disorders was found to be true. The result shows that the current level of ergonomics awareness in UPNM could be considered as at the beginner level. Fifty six presents of the respondents in the first instance relate ergonomics to health, back pain and work-related injuries separately. More than 50\% reported moderate pain and soreness at various parts of their body. Therefore, the next step of ergonomics intervention that could be introduced is to educate them through educational tools and expert talks.
\end{abstract}

\section{Introduction}

OSHA's definition of Ergonomics is fitting the task to the worker. Health problems such as work musculoskeletal disorders (WMSDs) and repetitive syndrome injuries (RSIs) are commonly reported by office workers worldwide [1] especially for workers who associated with video display units or terminals (VDU or VDT), keyboard and the mouse [2]. The common characteristics that contribute to WMSDs are repetitive movements, sustained postures and incorrect postures. Sitting incorrectly and prolonged static positions increase the biomechanical stress at the lower and upper back, neck and shoulders which is categorized as the upper limb of a human body. The activity to sustain non-neutral postures during computer use, such as neck rotation and shoulder abduction are defined as risk factors [3].

Ergonomics activities in industrial developing countries mainly began during the early 1960s [4], however Sen [5] suggested some work has been carried out earlier as early as 1953 in India. Ergonomics in Malaysia was formally introduced through the establishment of ergonomics division in the National Institute of Occupational Safety and Health (NIOSH in late 1992 [6]). Most 
occupational ergonomics researches were industrial-based [7-9]. In the beginning, ergonomics at workplace can be found in companies originated from multinational manufacturing industries. It is difficult to convince the Malaysian that ergonomics is actually economics. Yeow and Sen [10] claimed that there are five main reasons that contribute to the challenge. First is the low level to none of knowledge regarding ergonomics. Second is the wrong perception that most people have, ergonomics is always associated to expensive cost whereas it is the other way around. Ergonomics is actually an investment that protects workers from injuries and health problems, hence higher productivity and motivation. Third is low level of education among the workers themselves. Fourth, management take it for granted since cheap labour is still abundance in Malaysia. Finally, lack of support groups and professionals that could help promotes ergonomics to the public.

The underline is that ergonomics awareness among Malaysian is still low. Therefore, this study aims to determine the level of awareness among the office workers in an IHL. The results will help determine the suitable intervention programs for them. Since this IHL is still very young, prevention action can still be implemented before serious WMSDs and RSIs are found among the workers within the institute.

The hypothesis of this study is that the University workers have very little or no knowledge at all regarding ergonomics or office ergonomics and yet some of them might already experience workrelated musculoskeletal disorders and other occupational diseases. Following this hypothesis, there are several research questions that will shape the analysis and discussion of this study;

a. What do they understand from the term ergonomics in the first instance?

b. How is the prevalence of WMSDs among the respondents?

c. How does the type of the respondents' office works that contribute to ergonomics diseases?

Hence, this study embarks on the following objectives:
a. To investigate the level of ergonomics awareness among UPNM office workers
b. To study the prevalence of work-related musculoskeletal disorder syndromes among the office worker and the source of the risk
c. To develop a suitable ergonomics intervention program for the office worker in UPNM

\section{Methodology}

The population of this research was divided into three, the non-academic officers, the lecturers and the supporting staff in various departments, centres and faculties in UPNM. Table 1 illustrates the breakdown of staff in UPNM. Out of 120 staffs, only 50 respondents gave their feedback within the given period.

Table 1 The number of potential respondents

\begin{tabular}{lc}
\hline \multicolumn{1}{c}{ Categories } & No. of Respondents \\
\hline Non-academic officers & 40 \\
Lecturers & 40 \\
Supporting staff & 40 \\
\hline Total & 120 \\
\hline
\end{tabular}

Response rates are more important when the purpose of the study is to measure effects or make generalizations to a larger population. However it is less important if the purpose is to gain insight such as in this study. 
The instrument of this research was a series of questions based on the hypothesis and research questions described earlier. A set of questionnaire that has been used succesfully in another organisation was used again [11]. The survey was distributed via online service from surveymonkey.com, emails as well as using hardcopies. Survey questionnaires was distributed through emails as attachment as well as link to the online survey. Hardcopy questionnaires was distributed manually. The respondents were reminded to choose only 1 method of giving their feedback. The online survey provider however has the ability to filter redundant response from the same person.

\section{Results and Discussion}

There were 50 feedbacks, 36 responded through the email invitation, i.e. surveymonkey online survey and the rest was through hardcopy survey questionnaire. The responses were less than half than the number of potential respondents. This shows that it is quite difficult to persuade people to respond to survey questionnaires aand this must be anticipated at early stage of research. Sixty-two percents respondents were female, and this is also expected since most of the administrative staffs are female. About $46 \%$ of them aged between 20-29 years old and $28 \%$ are between $30-39$ years old.

The findings should be answering these research questions. The first was on the understanding of the term ergonomics in the first instance. Almost $56 \%$ of the respondents in the first instance relate ergonomics to health, back pain and work-related injuries, while the rest of the responses were scattered evenly to design of keyboard and computer's monitor and to design of office seat. These responses showed shallow knowledge on ergonomics as an academic discipline that covers many areas of science and social. However, the findings were expected as they are people with a layman view regarding ergonomics.

The second aim of the study was to identify suitable ergonomics intervention programs for the workers. Hence, according to the research question, the consecutive questions in the survey questionnaire should be related to musculoskeletal disorder symptoms. The findings showed the majority have been doing electronic keyboarding between 6-10 years (32\%) and 1-5 years (20\%). From the result, more than half of the respondents spend between 2-5 hours in a workday at the keyboard. Consequently, $72 \%$ of them use vision correction i.e. glasses or lenses. Respondents usually use mouse every day $(76 \%)$ and sometimes they take a break from sitting at the computer every 2 hours, (56\%); perform stretching exercise at their computer, $(58 \%)$; often do their job very fast, $(60 \%)$ and do repetitive jobs (62\%). Repetitive jobs could induce repetitive syndrome injuries and this is also not desirable in any work environment. Suitable intervention for this is to educate the workers so that they alternate their VDT and non-VDT duties and try not to sit more than 2 hours straight in front of their workstation. However, OSHA [12] stressed out that in order to avoid sore eyes, workers are advised exercise their eyes and to look away from the VDT screen every hour.

Other than that, findings show that $40 \%$ of the repondents complained that working in the same position for long periods (standing, bent over, sitting etc) as a severe problem to them. Although the majority showed appropriate sitting posture at the computer station which is shown in Figure 1, more than $50 \%$ of the respondents complained soreness, stiffness or pain at their neck (54\%), shoulder (58\%), upper back (52\%) and lower back (50\%). As shown in Figure 2, about 50\% of the respondents sometimes experienced moderate headache, sore eyes and/or blurry vision after computer use. About $40 \%$ of the respondents feel moderate stiff or sore neck and/or upper back, low back pain, sore or pain shoulder, sore or pain forearm or elbow and pain or numb hand/wrist. Although the pains were only moderate, if there is no prevention, it will accumulate and resulted as severe WMSDs. 

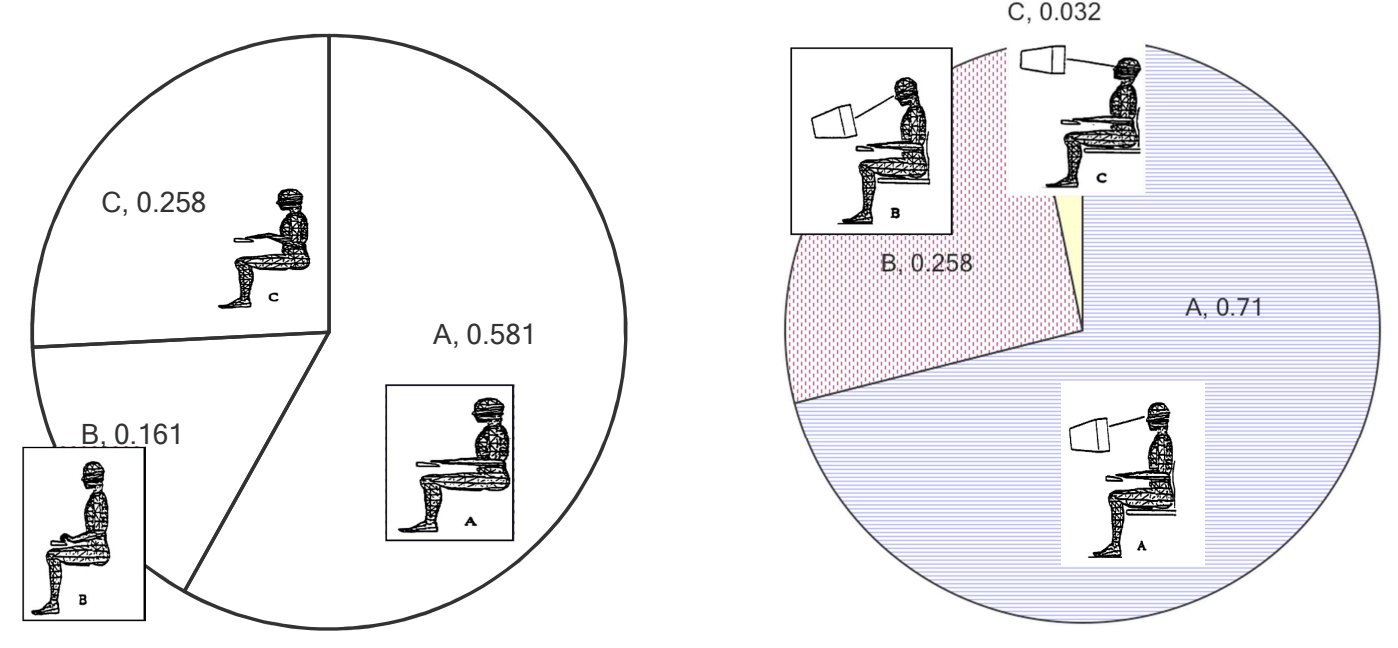

Figure 1 Preferred computer hand and head position

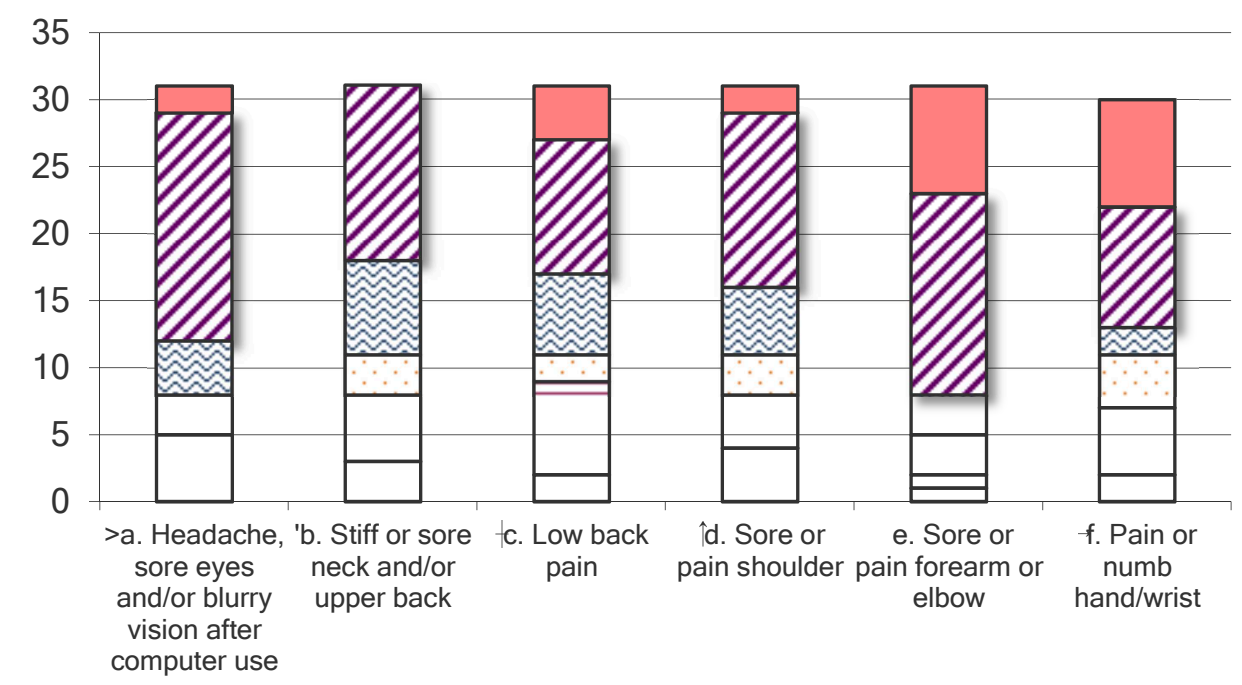

๑Severe $\square$ Moderate $\square$ Slightly 圆Usually $\square$ Sometimes $\square$ Never

Figure 2 Symptoms of musculoskeletal disorders

From the survey, it is concluded that an ergonomic assessment should be carried out before any ergonomic intervention program could be introduced. Hence, the hyphothesis of the study is true in which the workers have very little knowledge regarding office ergonomics and some already experience work-related musculoskeletal disorders especially at their back and their shoulder. The next stage of the study is to carry out the RULA assessment. At the same time, ergonomic awareness program must be carried out via various modes, i.e. educational flyers, frequent reminders through leaflets and talks from experts.

\section{Conclusion}

This case study indicated the lack of knowledge on ergonomics at work among the IHL workers. Although their reports suggest that they have not experienced severe WMSDs, in the long run, it might not be the same. From the moderate complaints, they are definitely exposed to further 
WMSDs risks. Hence, there is an urgent need to educate the IHL workers regarding WMSD and preventions that could be done. The results show that it seems the majority of the users are on the correct office ergomonic working postures. But there are still users who didn't know the importance of stretching their body and to alternate between VDT and non VDT duties. Furthermore, these responds were only for $40 \%$ of the workers.

\section{References}

[1] J. Sillanpaa, S. Huikko, M. Nuberg, P. Kivi, P. Laippala \& J. Uitti. 2003. Effect of work with visual display units on musculo-skeletal disorders in the office environment. Occup. Med. 53(7): 443-451

[2] B. Bidasse, J.D. McGlothlin, A. Goh, R.G. Feyen \& J.W. Barany. 2010. Limited economic evaluation to assess the effectiveness of a university-wide office ergonomics program. Applied Ergonomics 41:417-427

[3] P. Pillastrini, R. Mugnai, L. Bertozzi, S. Costi et al. 2010. Effectiveness of an ergonomic intervention on work-related posture and low back pain in video display terminal operators: a 3 year cross-over trial. Applied Ergonomics 41:436-443.

[4] S. Banerjee. 1962. Studies on Energy Metabolism. Indian Council of Medical Research. New Delhi. Special Report. 43:1-31.

[5] R.N. Sen 1984. Application of ergonomics to industrially developing countries. Ergonomics. 27:1021-1033.

[6] NIOSH, www.niosh.org.my

[7] Z.M. Makhbul, and D. Idrus. 2009. Work stress issues in Malaysia. Malaysia Labour Review. 3(2):13-26.

[8] S.A. Mustafa, S. Kamaruddin, Z. Othman and M. Mokhtar.. 2009. Ergonomics awareness and identifying frequently used ergonomics programs in manufacturing industries using quality function deployment. American Journal of Scientific Research. Issue 3: 51-66.

[9] B.M. Deros, D. Mohamed, A.R. Ismail, O.W. Soon, K.C. Lee \& M.S. Nordin. 2009. Recommended chair and work surfaces dimensions of VDT tasks for Malaysian citizens. European Journal of Scientific Research. 34(2): 156-167.

[10] P.H.P. Yeow and R.N. Sen. 2002. The promoters of ergonomics in industrially developing countries (IDCs) their work and challenges. Proceedings of 3rd CybErg 2002: The third international Cyberspace Conference and Ergonomics. In Thatcher, A., Fisher, J. and Miller, K. The International Ergonomics Association Press, University of the Witwatersrand, Johannesberg : 18-30.

[11] N.A. Samsuddin and D.D.I. Daruis. 2013. A study of musculoskeletal disorders among visual display terminal workers. International Conference on Ergonomics, Kuala Lumpur.

[12] OSHA 3092. 1997 (Revised). Working safely with video display terminals. US Department of Labor. 